\title{
MICHEL FOUCAULT: AS LUTAS EM TORNO DO PODER E A DINÁSTICA DO SABER
}

\author{
Cesar Candiotto* \\ ccandiotto@gmail.com
}

\begin{abstract}
RESUMO Neste artigo, objetivamos explorar os cruzamentos entre as lutas empreendidas por Michel Foucault no início dos anos setenta e o desenvolvimento de conceitos, como os de sobressaber e sobrepoder no curso "Théories et institutions pénales", a fim de entender como a insurreição dos saberes sujeitados, mencionada em "Il faut défendre la société", pode ser também identificada nos movimentos operários e em outras formas de luta, diante do excesso de saber posto ao serviço da concentração e burocratização do poder. Propomo-nos analisar ainda os desdobramentos teóricos da dinástica do saber, tratada em "Théories et institutions pénales" e em passagens de "Dits et écrits", principalmente pela sua diferença em relação à leitura althusseriana do conceito de ideologia. Nesse sentido, pretendemos indicar até que ponto o permanente afastamento foucaultiano do conceito de ideologia no começo dos anos setenta permitiu-lhe isolar a ideia de dinástica do saber como uma primeira delimitação da analítica do poder.
\end{abstract}

Palavras-chave Analitica do poder, dinástica do saber, sobrepoder, ideologia.

ABSTRACT In this paper we aim to explore the intersections between the struggles undertaken by Michel Foucault in the early seventies and the development of concepts such as over-learn and over-power in the course "Théories et Institutions pénales", in order to understand how the insurrection

* PUCPR/CNPq. Artigo recebido em 10/03/2016 e aprovado em 10/05/2016.

KRITERION, Belo Horizonte, no 135, Dez./2016, p. 659-675 
of subjected knowledges, mentioned in "Il faut défendre la société", can also be identified in labor movements and in other forms of clash, before the excessive knowledge put at the service of concentration and bureaucratization of power. We propose further examination on the theoretical developments of the dynastics of knowledge mentioned in "Théories et Institutions pénales" and in passages from "Dits et écrits", mainly because of its difference from Althusser's reading of that ideology concept. We intend to show to what extent the permanent removal of Foucault's ideology concept in the early seventies allowed him to isolate the dynastics of knowledge idea as a first delimitation of the analytics of power.

Keywords Analytics of power, dynastics of knowledge, over-power, ideology.

\section{Introdução e contexto do estudo}

Desde o final dos anos 1960, Michel Foucault intensifica seu engajamento político assim como redireciona sua investigação para a problemática do poder. Essa intensificação e esse redirecionamento podem ser lidos como o efeito direto do contexto histórico sobre seus ditos e escritos, ou ainda, o reflexo da vida militante sobre sua vida intelectual, ou enfim, a importância da contingência do presente sobre o seu diagnóstico teórico. Contudo, essa leitura causal é insuficiente e, até mesmo, temerária. Pensamos que a perspectiva mais apropriada a esse respeito é tentar relacionar sua vida militante e seu labor intelectual a partir de seus cruzamentos recíprocos e pelos seus deslocamentos no interior da problematização do poder. Essa escolha impõe mostrar até que ponto a analítica do poder - como ficou conhecida sua mais excelsa elaboração filosófica nos anos setenta - é devedora dos desdobramentos de Maio de 68, sem que, no entanto, ela seja somente sua consequência direta.

Para isso, é conveniente que se faça, ainda que de modo sumário, uma menção ao momento político francês do início dos anos 1970. Com a saída do general De Gaulle em abril de 1971 da Presidência da República e a eleição de Georges Pompidou, a nova orientação política consistiu em dar um basta às crises e agitações remanescentes do pós-68 em nome da necessidade de modernização e de reforma social. Foi fundamental a tentativa de diálogo social, de um lado; mas isso resultou, de outro, na repressão dos movimentos mais radicais e seus agentes. No entanto, como podemos ler no Manifesto de Fundação do Grupo de Informação sobre as Prisões (GIP) de 8 de fevereiro de 1971, do qual Foucault é cofundador, a repressão prevaleceu sobre o diálogo, e o aprisionamento se intensificou tornando qualquer um a ele vulnerável (Foucault, 2001a, p. 1042). 
O alvo principal da repressão é o movimento maoísta da Gauche prolétarienne. ${ }^{1}$ Seus dirigentes e os diretores de seu jornal, "La cause du peuple", haviam sido aprisionados. Foucault e Sartre apoiavam o movimento maoísta, sendo que Sartre assumiu em seguida a direção daquele jornal. Foucault, por sua vez, participou de vários de seus debates, notadamente sobre a justiça popular. Mesmo assim, um e outro mantinham reservas em relação aos maoístas. ${ }^{2}$

O controle intenso e a repressão ostensiva, direcionados primeiro contra os movimentos radicais de esquerda, foram em seguida estendidos às grandes universidades e instituições de ensino. Os intelectuais propuseram diversas formas de resistência, como a defesa da liberdade de expressão diante da repressão dos chamados delitos de opinião, ou ainda a criação do Secours Rouge, em 1970, para a defesa política e jurídica das vítimas da repressão. Portanto, o engajamento de diversos intelectuais em grupos de extrema esquerda tem uma relação com esse momento histórico e político preciso caracterizado pela acentuada repressão do Estado.

No caso de Foucault, Maio de 68 e os acontecimentos do início dos anos 1970 o influenciaram no nível do engajamento político, mas não necessariamente no da experiência da escritura como ação política. Ainda que, em entrevista a André Berten no dia 7 de maio de 1981, ele declare que trabalha "[...] ao léu das circunstâncias, das solicitações exteriores" (Foucault, 2012, p. 237), não convém tomar essa declaração ao pé da letra no sentido de tentar explicar a elaboração filosófica somente pelo contexto ${ }^{3}$ ou a obra somente pela vida. ${ }^{4}$

1 A Gauche prolétarienne (GP) era um movimento maoísta não leninista nascido da fusão entre o movimento estudantil antiautoritário de 22 de março de 1968 em Nanterre e do UJCML (Union des Jeunesses Communistes Marxistes-Léninistes, fundada em dezembro de 1966). Em maio de 1970, o governo dissolve o movimento, mas ele continua atuante nos anos seguintes, como no jornal "La cause du peuple" (cf. Defert, 2001, p. 48).

2 Entre elas, a recusa, da parte de Foucault, do tribunal popular contra a polícia, como havia sido o caso do tribunal instaurado pelo Secours Rouge em 1970, na cidade de Lens, em defesa dos aprisionados maoístas (Ewald, Harcourt, 2015, p. 250); ou a crítica de Sartre ao movimento quando eles invocaram o linchamento do notário de Bruay-en-Artois que, supostamente, havia assassinado um jovem operário (cf. Christofferson, 2014, p. 147).

3 Essa é uma tentação que provém principalmente dos sociólogos e historiadores que frequentam o pensamento de Foucault. Limito-me a indicar dois artigos que tentam mostrar como os interesses teóricos de Foucault mudavam e deslocavam-se em vista de sua busca de reconhecimento como intelectual na mídia parisiense: cf. Christofferson, In: Zamora, 2014, pp. 13-35; e Behrent, In: Zamora, 2014, pp. 37-85. Para uma crítica dessa tentação do contextualismo como explicação das posições teóricas de Foucault, ver a resenha de Leonardi (2014).

4 Essa é a posição de Miller (2000). A esse respeito, consideramos muito mais prudentes as posições de Macey (1994), bem como a de Eribon (1989). Essa prudência consiste em mostrar como a vida (pessoal e militante) de Foucault se entrecruza com suas elaborações teóricas, sem, porém, que essas últimas sejam reflexos dela. Temos que levar em consideração, quando se trata do engajamento político de Foucault nos anos 1970, a presença e a proximidade de Daniel Defert em sua vida pessoal e militante, o qual, em entrevistas publicadas em 2014, narra sua própria vida como uma vida política (cf. Defert, 2014). 
A partir de 1968, as lutas contra o internamento manicomial e o aprisionamento tornaram-se repentinamente centrais no mundo intelectual e em meio à população francesa. Entretanto, Foucault já havia feito a arqueologia do silenciamento da loucura em "Histoire de la Folie" entre o final dos anos 1950 e sua publicação em 1961. Praticamente ignorada pela crítica em sua primeira edição, aquela que foi sua tese doutoral escrita em Upsala é reeditada na efervescência política de 1972, provocando diversas intervenções e discussões (cf. Foucault, 2001b, p. 89). A relativa extemporaneidade desse livro pode ser uma das razões pela qual Foucault não considera as lutas antimanicomiais e antiprisionais do pós-68 tão revolucionárias como se imaginou. Na verdade, ele considera as manifestações estudantis francesas de 1968 bem confortáveis em comparação à radicalidade do movimento estudantil comunista tunisiano, em favor do qual ele colaborou intelectual e financeiramente na mesma época. Essa advertência serve para lembrar que algumas análises de Foucault precedem o estudo de problemáticas que se popularizam no pós-1968. Se, de um lado, é conveniente situá-las a partir de seu contexto histórico e político, de outro, o contextualismo não é uma estratégia suficientemente adequada para entender um pensamento movente que, em certa medida, se antecipa à sua própria época. O contex to é então indicativo, e portanto jamais determinante, para estudar os deslocamentos internos que constituem a emergência da analítica do poder. Em contrapartida, a relação entre contexto histórico-político e elaboração teórica a partir de seus cruzamentos é, a nosso ver, a estratégia metodológica mais adequada para situar seu trabalho investigativo naquele momento.

\section{A emergência da analítica do poder}

Até 1994, ano em que foram publicados os "Dits et écrits", a analítica do poder era conhecida principalmente a partir dos livros dos anos 1970, "Surveiller et punir" (1975) e "La volonté de savoir" (1976). Ainda que os "Dits et écrits" tenham ampliado sua compreensão, pensamos que, após a edição completa dos cursos no Collège de France em 2015, ela deverá ser repensada, principalmente no início de sua elaboração. Nesse sentido, o curso de 1971, "Leçons sur la volonté de savoir" (2011); ${ }^{5}$ o de 1972, “Théories et Institutions Pénales” (2015);

5 Ao final do curso de 1971, Daniel Defert edita a Conferência pronunciada na Universidade McGrill, em Montreal, de abril de 1971, intitulada "Leçon sur Nietzsche, comment penser l'histoire de la vérité avec Nietzsche sans s'appuyer sur la vérité" (Foucault, 2011, pp. 195-213), que em seu começo antecipa a primeira das conferências no Rio, "La vérité et les formes juridiques"; também é anexado ao curso "Le savoir d'Oedipe", na verdade uma segunda versão da lição de 17 de março de 1971, resultado de uma conferência dada em março de 1972, na State University of New York, em Buffalo (Foucault, 2011, pp. 
e o de 1973, "La société punitive" $(2013)^{6}$ chamam-nos a atenção para um processo menos evidente e acabado. Muito pelo contrário, estamos diante da possibilidade de fazer a genealogia da emergência dessa analítica.

Nesses textos, encontramos uma série de deslocamentos lentos e complexos, ${ }^{7}$ assim como a ênfase em problemáticas que não são desenvolvidas mais tarde; ${ }^{8}$ ou, quando o são, tornam-se menos evidentes nos livros de 1975 e 1976 . Esses cursos também têm uma relação muito próxima com dois textos muito conhecidos na recepção brasileira: o artigo "Nietzsche, la généalogie, l'histoire" (1971) para compreender a inspiração de seu método e objeto de estudo, assim como as conferências no Rio de Janeiro, "La vérité et les formes juridiques" (proferidas em maio de 1973 e publicadas em junho de 1974), nas quais encontramos uma espécie de síntese dos primeiros três cursos no Collège de France.

O conjunto desses trabalhos pode apontar um novo olhar sobre a emergência da analítica do poder que constatamos de maneira amadurecida nos livro de 1975 e 1976. Essa bibliografia de Michel Foucault, recentemente editada, impõe àqueles que estudam seu pensamento a tarefa de redimensionar a quantidade expressiva de artigos, prefácios, conferências, debates e livros da primeira metade dos 1970 em torno da relação poder-saber.

Nosso objetivo é enfatizar a importância das lutas pelo poder e pelo saber como uma perspectiva de leitura dessa analítica. E, entre essas lutas pelo poder, aquelas que giraram em torno da técnica e do saber operário. Na medida do possível, queremos mostrar que ele não se detém no mero militantismo nessa época, mas que, em relação a ele, desenvolve uma pesquisa teórica de grande envergadura, diante de outras formas de pensar a luta social, principalmente as de inspiração marxista.

223-253). Pela data dessa palestra, mas também pela introdução da análise das práticas jurídicas, talvez ela coubesse muito melhor como anexo do curso de 1972, "Théories et institutions pénales".

6 Sobre "La société punitive", cf. a resenha de Picard (2014) e o artigo de Gros (2010).

7 Algumas dificuldades de apreensão conceitual apresentam-se para o estudo dos cursos de 1971 e 1972. A principal delas é a ausência da oralidade de Foucault na transcrição e edição desses cursos, exceto breves passagens. O curso de 1971 tem esquemas de apresentação manuscritos mais longos e precisos, enquanto que o de 1972 é excessivamente esquemático. Em contrapartida, o curso de 1973, o primeiro transcrito a partir dos manuscritos e do registro oral, dispõe das aulas completas.

8 Não é o caso de antecipar aqui o conjunto dessas problemáticas. Somente de modo indicativo, no curso de 1972 temos o estudo detalhado das revoltas do século XVII, o qual não será retomado em "Surveiller et punir", a não ser en passant. Identificamos ainda uma "genealogia da vagabundagem" no curso de 1973 que não encontramos em "Surveiller et punir"; ou ainda, uma análise dos ilegalismos muito mais ousada em 1973 do que o lugar que ela ocupa no livro de 1975. 


\section{As lutas em torno do poder e do saber operário}

No início dos anos 1970, Foucault é muito sensível às lutas políticas em torno da causa operária. No jornal "Libération", ele se empenha em publicar trabalhos da memória dos trabalhadores. Reconhece, por exemplo, que muitos dos documentos que Marx consultou para suas construções teóricas sobre a revolução do proletariado foram elaborados pelos próprios operários a respeito de suas condições de trabalho no início do século XIX, documentos estes importantes para suas práticas políticas e sindicais. Neles, o que se tinha era um saber técnico e um saber político. Como ele aponta na entrevista "Par-delà du bien et mal", de 1971 (2001a), ${ }^{9}$ na revista “Actuel”, o saber técnico operário foi objeto de constante extração, tradução e transformação por parte do patronado e dos quadros técnicos do sistema industrial. A partir da divisão do trabalho e graças a ela, é desenvolvido um mecanismo de apropriação que "mascara, confisca e desqualifica o saber operário" (Foucault, 2001a, p. 1093). E, em seguida, é seu saber político baseado no "conhecimento de sua condição", na "memória de suas lutas" e na "experiência de suas estratégias" que é desapropriado e, até mesmo, excluído pelo saber acadêmico, o qual foi instrumento de combate da classe operária e elaborado a partir desse combate.

No contexto dessa entrevista com um grupo de secundaristas, Foucault quer mostrar até que ponto os saberes oficiais, ensinados no Ensino Médio, tratam de representar o poder político a partir da luta no interior das classes sociais, seja pelas querelas dinásticas no interior da aristocracia, seja pela luta entre aristocracia e burguesia, porém excluindo dessas lutas pelo poder os movimentos populares, tais como o movimento operário. Por certo, o saber oficial da academia jamais representa o operariado a partir de sua luta pelo poder, mas somente em virtude de sua demanda por comida ou emprego. Foucault participa dessa conversa em novembro de 1971, porém, em sua retranscrição em 1973, na qual observamos modificações por meio de notas, ele procura mostrar o caráter repressivo e excludente desse saber com aparência positiva e neutra. Isso é comum nos conteúdos de história. Como diz Foucault, trata-se da

exclusão daqueles que não têm direito ao saber; ou que têm direito somente a um tipo de saber; imposição de uma certa norma, de uma certa grade de saber que se esconde sob o aspecto desinteressado, universal, objetivo do conhecimento; existência do que poderíamos chamar os 'circuitos de saber reservados', aqueles que se formam no interior de um aparelho de administração ou de governo, de um aparelho de produção, e aos quais não se pode ter acesso do exterior (Foucault, 2001a, p. 1092). 
Foucault valoriza a escrita sobre as condições de trabalho dos operários retratada por Marx no século XIX como a tentativa de reavivar a memória ao mesmo tempo técnica e política. ${ }^{10}$ Em vez de extrair ou expropriar o saber técnico e a memória política dos operários, de filtrar seu discurso e depois falar em nome deles, ele considera que o intelectual deve atuar como o facilitador de sua livre expressão. Ao enfatizar o contrassaber dos operários, pretende-se mostrar que sua luta não se restringe somente à luta contra o desemprego, mas que ela se estende ao enfrentamento do próprio poder político. O risco do saber do intelectual é justamente reproduzir o mesmo confisco daquele contrassaber, como se fez no século XIX a respeito do saber operário. ${ }^{11}$

Essa argumentação é um ponto-chave para a diferença feita entre intelectual universal e intelectual específico, que lemos na clássica conversação com Deleuze, em 4 de março de 1972. O intelectual específico age contra as formas de poder ali onde elas interditam o discurso e mascaram o saber das massas. Se o intelectual universal - como parecia ser o caso do lugar ocupado por Sartre - dizia a verdade em lugar de quem não tinha voz e o identificava à categoria do proletário ${ }^{12}-$, Foucault, por seu turno, quer sublinhar a força da memória das lutas políticas daqueles que historicamente foram silenciados e tornados inaudíveis a partir de uma ampla genealogia de seus saberes. Esses saberes têm sido normalmente sujeitados pelos arranjos funcionais e pelas organizações sistemáticas presentes nas fábricas. ${ }^{13}$

10 Podemos incluir também, nesse sentido, os seminários de 1972 e 1973 no Collège de France; consagrados ao estudo e à preparação da publicação do dossiê do caso Pierre Rivière. Esse assassino desconhecido do século XIX, depois de ter enforcado sua mãe, seu irmão e sua irmã, escreveu uma memória, publicada em 1836, em uma revista médica, que foi dirigida ao juiz e ao encarregado de fazer sua expertise psiquiátrica.

11 O saber dos "infames" ou daqueles tornados invisíveis e inaudíveis por parte do poder é portador de uma "verdade" ou de um "segredo" não capturado por aqueles que exercem o poder político ou o poder do discurso. Entende-se, nesse aspecto, por que foi escolhido o termo "informação" e não "inquérito" para nomear o GIP. A justiça e seu aparelhamento pelo Estado na Idade Média são estudados a partir do par inquérito/confissão (enquête/aveu), na lição de 8 de março de 1972. A esse respeito, parece ter ocorrido uma tensão entre duas genealogias do inquérito: uma primeira em 1970 na versão grega da formação das formas jurídicas, cujo jogo da verdade tem como referência o humilde, o pastor, enfim, aquele que viu e enuncia a verdade contra seus tiranos e senhores; outra, que prevaleceu na Idade Média, "fundada na administração e formação do aparelho judiciário do Estado, no qual aquilo que é notório é estabelecido pelos notáveis e/ou extraído por um conjunto de dispositivos de poder" (Doron, 2015, p. 224, nota 38).

12 Essa posição de Sartre muda sensivelmente desde o outono de 1970, a partir de seus contatos com os maoístas e de suas reflexões sobre maio de 1968. Como sublinha Christofferson (2014, p. 148): "Sartre opõe, desse modo, o novo intelectual ao intelectual clássico. Esse último toma consciência da contradição entre o caráter universal de seu trabalho e a atenção que ele dirige ao particular. Para tranquilizar sua consciência infeliz, o intelectual clássico denuncia os usos particulares do universal e elabora os princípios de uma política universal. Sartre encontra essa posição insuficiente no início dos anos 1970 . O novo intelectual deve prefigurar a sociedade universalista para a qual ele luta, na qual os clérigos não formarão uma categoria social separada, bem como ele deve contestar seu monopólio particular do saber, seu próprio estatuto de intelectual.".

13 A partir de 1971 é que podemos melhor compreender o tema da "insurreição dos 'saberes sujeitados', tratados na aula de 7 de janeiro de 1976, a propósito do saber do psiquiatrizado, do médico, "mas paralelo e 
Ainda que nosso estudo se concentre no exemplo das lutas operárias, sabemos que Foucault as posiciona ao lado de outras formas de lutas, tais como aquela empreendida contra o poder prisional, o poder médico e o dispositivo da sexualidade. Dessa perspectiva é que pode ser entendido seu trabalho de arquivo realizado desde "Histoire de la folie" sobre o aprisionamento/internação no Hospital Geral e na Bastilha, e que se expande bem mais tarde por ocasião da introdução a um projeto antológico intitulado "La vie des hommes infâmes" (Foucault, 2001b, pp. 237-253) que, a partir de 1978, se torna a coleção "Les Vies parallèles", na qual é publicada a memória de "Herculine Barbin dite Alexina B" (Foucault, 2014); ou ainda, "Le Cercle amoureux d'Henri Legrand", esse último conservado como manuscrito na Biblioteca Nacional. Nele também se inclui o livro "Le désordre des familles", de 1979, em colaboração com a historiadora Arlette Farge (Farge, Foucault, 2014).

\section{A insurreição dos saberes sujeitados}

Pretendemos relacionar esses elementos em torno das lutas pelo poder e pelo saber a uma aula no Collége de France que opera como uma charnière entre, de um lado, algumas considerações de "A arqueologia do saber" (de 1969) e "Leçons sur la Volonté de savoir" (de 1971) e, de outro, um conjunto relativamente amplo de intervenções no começo dos anos setenta a respeito do saber e do poder. Trata-se da aula de 8 de março de 1972 do curso "Théories et institutions pénales" que, na sua segunda parte, é intitulada "Remarques complémentaires à propos du système pénal et des effets de savoir" (Foucault, 2015, p. 204). Ela é escolhida não somente porque redimensiona teoricamente essas lutas em torno do saber e do poder, mas também pela sua contemporaneidade ao diálogo entre Foucault e Deleuze, "Les intellectuels et le pouvoir", ocorrido quatro dias antes. Não pretendemos recompor a dinâmica do curso de 1972 para tratar dessa aula, que é a última daquele ano, o que extrapolaria os objetivos de nosso estudo. Tentamos somente mostrar o cruzamento entre as lutas empreendidas por Foucault e o desenvolvimento teórico de sua analítica em torno das formas de saber-poder, tomando agora como exemplo as práticas judiciárias.

O primeiro aspecto a ser destacado da aula de 8 de março é a importância da forma saber-poder no processo de constituição do sujeito. Durante seus dois

marginal em relação ao saber médico, aquele do delinquente", e uma gama de "saberes das pessoas", que não se identificam com o senso comum ou com o bom senso, mas como saberes locais, desqualificados a partir dos quais se trata de empreender a crítica (Foucault, 1997, pp. 8 e 9). Os saberes sujeitados designam, pois, tanto os saberes eruditos, porém não conceituados ou insuficientemente elaborados, quanto o saber das pessoas comuns. 
primeiros cursos no Collège de France, Foucault tratou longamente sobre duas formas de saber-poder, identificadas a partir de suas matrizes jurídico-políticas: a medida, entre os gregos; e o inquérito, entre os medievais. Privilegiamos essas duas formas porque elas ocupam um lugar singular nos seus dois primeiros cursos e porque elas têm desdobramentos relevantes em outros trabalhos de Foucault.

Duas diferenças são apresentadas entre elas e aqui tratamos somente de sumarizá-las. Uma primeira diz respeito ao nível das formas: a medida serve para distribuir as coisas, ao permitir a recomposição de quantidades a partir de um saber preliminar. ${ }^{14} \mathrm{O}$ inquérito, por sua vez, não supõe um saber preliminar; ele consiste na extração do saber dos objetos, seu deslocamento e conversão em informação, a fim de que, a partir do acúmulo dessa informação, o governante tome uma decisão. Uma segunda diferença entre inquérito e medida concerne ao nível de seus efeitos: quando se trata da medida, do modelo de saber-poder grego, o sujeito político pode ser o cidadão ou o governante. Um e outro devem ser justos e, portanto, exercer a moderação, para recompor a justa-medida. ${ }^{15}$ Somente há uma boa medida na adequada distribuição dos bens ou do poder se ela primeiro for adquirida subjetivamente, o que explica a importância da educação para a formação do cidadão e do governante. Um bom governante ou um bom cidadão devem se aprimorar no estudo da geometria a fim de conhecer a correta medida e as proporções, assim como não podem deixar de buscar a sabedoria: aquele que tem mais poder deve ser o mais avançado no saber, conforme o tema clássico do governante filósofo. A diferença com o inquérito medieval é que este não é um saber-formação, mas um saber-informação. Trata-se do saber concentrado, e é o que Foucault denomina de sobressaber, o qual não exige ser subjetivado, bastando que esteja sempre disponível ao governante, para que ele tome suas decisões quando dele precisar. No inquérito e a partir dele o modelo da pedagogia é substituído pelo da burocracia (Foucault, 2015, p. 211). O

14 A passagem mais expressiva é a da aula de 24 de fevereiro de 1971, na qual Foucault relaciona medida e moeda. "Antes de se inscrever na consciência ocidental como o princípio de quantificação, da harmonia, do non-excesso clássico, a medida grega, não devemos esquecer, foi uma imensa prática social e polimorfa de estimação, de quantificação, de equiparação, de pesquisa das proporções e das distribuições adequadas" (Foucault, 2011, p. 128).

15 Aqui Foucault introduz uma dimensão da "medida" a partir do conceito de métron no sentido "não excessivamente nem demasiado pouco" [ni trop ni trop peu], atribuído pela primeira vez a Sólon, depois a Hesíodo, para o qual o métron, é tanto o cálculo quanto a norma (Cf. Foucault, 2011, p. 127). A moeda justamente exercia inicialmente esse papel de métron: "A moeda é, pois, antes de tudo, um instrumento de regulação entre os diferentes elementos que constituem a cidade: pela distribuição de moeda [sob] forma de presentes e doações, evita-se que os pobres se tornem excessivamente pobres; pelo imposto recolhido sobre os ricos, evita-se que não sejam excessivamente ricos" (Foucault, 2011, p. 136). O conceito de métron encontramos, mais tarde, na "Ética a Nicômaco", como elemento constitutivo da definição de "areté" (de excelência) cuja subjetivação corresponde ao homem virtuoso, seja o cidadão ou o governante (cf. Aristóteles, 1973, p. 273 ss.). 
escopo deixa de ser a formação de cidadãos e governantes para a justa-medida; a prioridade doravante é a produção de "burocratas, administradores, elementos para o processo de acumulação, circulação, registro do saber" (2015, p. 211).

No curso de 1972, Foucault concentra-se na extração do sobressaber sob a forma do inquérito e a constituição do sujeito a que ela deu lugar, como é o caso do nascimento das figuras do "investigador/inquisidor" e do "notável". O primeiro é considerado o "instrumento de extração, até mesmo de concentração, instrumento direto ou indireto do aparelho de Estado ou do poder"; quanto ao segundo, a transcrição do curso designa como "aquele que sabe e que aceita que seu saber seja extraído, e quem já o extraiu; testemunho e garante, mas que pode recusar a verdade" (Foucault, 2015, p. 211). A propósito da figura do notável é que podemos justamente estabelecer um cruzamento entre a interpretação da forma saber-poder do inquérito medieval no interior das práticas judiciárias, da aula de 8 de março, e a discussão entre Foucault e Deleuze no dia 4 de março sobre os intelectuais e o poder.

Foucault considera que essa figura que sabe e que aceita que seu saber seja extraído ou expropriado pode ser relacionada ao intelectual, pelo menos no contexto dos debates realizados em torno de seu estatuto no final dos anos 1960 e no início dos anos 1970. Consoante à aula de 8 de março, o notável encontra-se em uma posição menos definida que a do inquisidor: próximo do aparelho do Estado e "preste a se tornar funcionário"; mas também sempre pronto a ser, como escreve Foucault, um "intelectual 'contestatório', fora do jogo, que recusa extrair o saber (casos do poeta e do escritor), ou que pretende colocar seu saber ao serviço da classe dominada" (Foucault, 2015, p. 211). O intelectual, portanto, tem à sua disposição a possibilidade de subverter o modelo de saber concentrado do inquérito e a serviço do sobrepoder.

As elaborações teóricas dessa aula de 1972 vão ao encontro do trabalho que Foucault e outros intelectuais desenvolvem no Grupo de Informação sobre as Prisões. No GIP, não se trata de produzir um discurso racional sobre os prisioneiros, de extrair seu saber para sua acumulação. A "informação" recolhida a partir dos questionários distribuídos, e depois publicados, não tem o mesmo tipo de extração que os inquéritos ou investigações administrativas. Foucault e outros membros do GIP pretendiam subverter o modelo administrativo do inquérito pela utilização de suas próprias armas ao publicarem um discurso que ninguém sabia e, desse modo, proporem uma modalidade de resistência ao poder político e ao sobrepoder do sistema carcerário. Em lugar do excesso de obediência ao poder, o intelectual contestatório tem como contribuição fundamental incitar a insurreição dos saberes sujeitados. Não se trata mais do saber do acúmulo e de seu estoque inútil e que, no entanto, sustenta o sobrepoder; 
antes, são os saberes das experiências prisional e operária, marcados pela raridade, pelo acontecimento da revolta contra o excesso de saber. Temos, portanto, um primeiro cruzamento do trabalho teórico de Foucault com seu engajamento político em torno do saber e do poder.

\section{A dinástica do saber}

A relação que Foucault estabelece, desde 1971, entre saber e poder tem ainda como pano de fundo a tentativa de se desprender do esquema da ideologia ou, pelo menos, mostrar sua insuficiência. ${ }^{16}$ Essa tentativa pode ser identificada como um segundo cruzamento entre a emergência da problemática do podersaber e as discussões à época em torno do conceito de ideologia. Não se trata aqui de inventariar todas as tentativas de distanciamento desse conceito no percurso dos livros e cursos; antes, procura-se observar como ele é debatido no contexto da aula de 8 de março de 1972.

Nesse momento, Foucault enfatiza o seguinte:

poder e saber não estão ligados, um ao outro, somente pelo jogo dos interesses e das ideologias; o problema não é somente então o de determinar como o poder se subordina ao saber e o faz servir aos seus fins, ou como o primeiro se sobre-imprime ao segundo e lhe impõe conteúdos e limitações ideológicas. Nenhum saber se forma sem um sistema de comunicação, de registro, de acumulação [grifos nossos], de deslocamento que é, em si mesmo, uma forma de poder e que está ligado, na sua existência e no seu funcionamento, a outras formas de poder. Em contraposição, nenhum saber se exerce sem a extração, a apropriação, a distribuição ou a retenção de um saber. Nesse nível, não há o conhecimento de um lado, e a sociedade de outro, ou a ciência e o Estado, mas as formas fundamentais do "saber-poder". (Foucault, 2015, p. 231, tradução nossa)

Todo exercício de poder é ao mesmo tempo o lugar de formação, não da ideologia, mas do saber. A valorização da ideologia para interpretar os efeitos superestruturais da reprodução das relações de produção e seu processo de acumulação era comum entre Althusser e seu círculo. Não era raro que nesse círculo a ideologia sempre fosse considerada um elemento negativo a partir do qual a relação do sujeito com a verdade [com seu ser autêntico] é obscurecida pelas suas condições de existência, pelas relações sociais ou pelas formas políticas "que se impõem do exterior ao sujeito de conhecimento" (Foucault, 2001a, p. 1420). Por certo, Althusser entende que "toda ideologia tem por função [...] 'constituir' os indivíduos concretos em sujeitos”' (Althusser, 2011, p. 295).

16 Todo exercício de poder é ao mesmo tempo o lugar de formação, não da ideologia, mas do saber. Essa tentativa de valorização da ideologia para interpretar os efeitos superestruturais da reprodução das relações de produção e seu processo de acumulação era comum em Althusser e seu círculo. 
Foucault insiste em se afastar desse recurso metodológico. Ele pretende mostrar "como, de fato, as condições políticas, econômicas de existência não são um véu ou um obstáculo para o sujeito de conhecimento, mas aquilo através do que se formam os sujeitos de conhecimento" (Foucault, 2001a, p. 1421; cf. Foucault, 2015, p. 206). A desconfiança recorrente nutrida pelo conceito althusseriano de ideologia deve-se ao corte simplista estabelecido entre ciência e não ciência (Foucault, 1969, pp. 240-243), além de que o conhecimento é pensado como uma relação já dada entre sujeito e objeto.

Em 1972, Foucault aponta como o conhecimento científico disseminado pela instância supostamente independente, autônoma, neutra e desinteressada da Universidade procura esconder que, "na raiz do saber que ela distribui, há a extração do sobressaber" (Foucault, 2015, p. 212). ${ }^{17}$ A hierarquia descendente, mas jamais ascendente, entre Universidade-Liceu-Escola impede a constituição de um saber popular, pois ela restringe às classes populares uma "forma de educação canonicamente estabelecida", ${ }^{18}$ ao mesmo tempo que suas técnicas e seu saber empírico são extraídos e transformados em sobressaber neutro e desinteressado. De onde a necessidade de mascarar a formação desse sobressaber, invertendo sua formação a partir de algumas precauções, como as separações entre técnica e ciência, saber empírico e conhecimento científico.

A genealogia de Foucault propõe-se a diagnosticar "como foi produzido esse sobressaber cujo efeito é a ciência ou o que é apresentado como ciência" (Foucault, 2015, p. 212). Não é negada a "continuidade" entre saber popular (técnico, empírico) e conhecimento científico; o que se tenta enfatizar é que esse entre, a partir do qual eles estão posicionados em planos diferentes, não é da ordem do "limiar de cientificidade" (Bachelard) ou da "ruptura epistemológica" (Althusser). ${ }^{19}$ Essas duas noções (limiar e ruptura) já sejam talvez a transposição dessa máscara, a tentativa de ocultamento da produção do sobressaber. A noção

17 Interessante é notar que Foucault fala de "extração" e não de "reprodução", este segundo conceito amplamente utilizado por Pierre Bordieu e Jean-Claude Passeron em seu livro "La Reproduction" (Paris: Editions de Minuit, 1970), no qual se destaca a relação entre os aparelhos de produção e o aparelho escolar. Esses autores consideram que a escola produz ilusões cujos efeitos são reais, tal como a ilusão da independência e neutralidade escolares, a qual constitui o princípio da contribuição mais singular que a Escola oferece à reprodução da ordem estabelecida.

18 Na entrevista de 1971, "Par-de là le bien et le mal", Foucault indica como o modelo da história e seu ensino tem um caráter repressivo à medida que ele impõe um conteúdo a ser recebido e outro a ser excluído ou ignorado. E isso é exemplar quando se trata de representar o poder político, quase sempre transmitido como uma luta no interior das classes (ou da aristocracia, ou da burguesia) ou entre as classes (burguesia e aristocracia). Quando se trata dos movimentos populares, quase sempre são vistos como lutas contra o desemprego, a fome e os impostos, mas quase nunca como uma luta pelo poder, "como se as massas pudessem sonhar em comer bem, mas certamente não de exercer o poder" (Foucault, 2001a, p. 1092).

19 Etienne Balibar lembra que, na época em que Foucault lê a teoria da ideologia a partir da ideia de ruptura epistemológica, "Althusser já havia publicado textos que se distanciavam da ideia de 'ruptura epistemológica', ao 'politizar' a relação entre ideologia e história, mas é preciso dizer também que esses textos eram 
de máscara, frequentemente utilizada por Althusser, é ironicamente colocada contra ele mesmo, quando Foucault cogita até que ponto seu esquema ciência/ ideologia é ideológico ao ocultar as relações de poder que o formaram.

$\mathrm{O}$ desvio do esquema da ideologia já havia sido feito em "L'archéologie du savoir" e "Les mots et les choses", "ao passar das ciências, ou das assim chamadas ciências, a grandes tipos de práticas discursivas, e pelo intermédio de "matrizes epistemológicas" (Foucault, 2015, p. 214). ${ }^{20}$ Em 1966, ele tenta mostrar que o marxismo não introduziu "nenhuma ruptura real", pois ele se alojou confortavelmente na disposição epistemológica do século XIX, que o acolheu e lhe deu lugar e, nesse aspecto, “o marxismo é, no pensamento do século XIX, como peixe dentro d'água: ou seja, que em qualquer lugar fora dela ele deixa de respirar" (Foucault, 1966, p. 274). ${ }^{21}$ No curso de 1972, ele ressalta que a análise dessas "matrizes epistemológicas" (no sentido de épistémès) "permite descobrir as maneiras de decompor, de quadricular, de constituir campos de objetos, de definir posições do sujeito, de regular a formação dos conceitos e teorias. Passa-se assim, por intermédio dessas matrizes epistemológicas, da descrição histórica das ciências à sua 'arqueologia"' (Foucault, 2015, p. 214).

Um segundo deslocamento metodológico, identificado por Foucault no curso de 1972, "permite passar das práticas discursivas para o nível do podersaber mediante o isolamento das matrizes 'jurídico-políticas' da medida e do inquérito" (Foucault, 2015, p. 214). Por certo, "é como analisadores das relações de poder-saber que as práticas judiciárias são tratadas, e não como reveladoras de uma ideologia" (Foucault, 2013, p. 14). Aqui a referência é o deslocamento operado entre "L'archéologie du savoir" e o curso de 1971, "La volonté de savoir".

De maneira sucinta, Foucault esquematiza esses dois deslocamentos na aula de 8 de março de 1972 da seguinte maneira:

- a história das ciências a partir da qual a redução das matrizes epistemológicas permite passar

- à arqueologia do saber: a partir da qual o isolamento das matrizes jurídicopolíticas do saber

fragmentários e contraditórios, e que Foucault se aproveita disso, por sua vez, para escolher sistematicamente a interpretação mais científica e atribuí-la a Althusser" (Balibar, 2015, pp. 286-287).

20 O adjetivo da expressão "matrizes epistemológicas", no caso de "Les mots et les choses", deve ser referido à noção de épistémè, e não à de epistemologia.

21 Essa posição do pensamento de Foucault a respeito do marxismo também estava direcionada a Sartre, para o qual o marxismo havia sido definido como "horizon indépassable de notre temps". Para uma análise contextual da relação de Foucault com Marx e o marxismo em "Les mots et leschoses", cf. Garo (2011, pp. 107-122). 
- permite passar ao nível do saber-poder. Nivel onde se vinculam a mais-valia, o sobrepoder e o sobre-saber. Estudo da dinástica do saber. (Foucault, 2015, p. 215).

Esse esquema indica a importância da arqueologia do saber ou, pelo menos, o isolamento de uma matriz particular de saber (a jurídico-política) para a genealogia das relações entre saber e poder. No entanto, antes de designar essas relações como "genealogia" e depois de ter elaborado uma "arqueologia" do saber, Foucault referiu-se ao seu trabalho como um estudo da "dinástica do saber”. Essa expressão, presente pela primeira vez em 8 de março de 1972, também é mencionada em maio de 1973, na segunda conferência de "La vérité et les formes juridiques", ocasião na qual Foucault sublinha que ele, Deleuze, Guatarri e Lyotard fazem pesquisas de dinastia. ${ }^{22}$

Eu diria, jogando com as palavras gregas dunamis e dinasteia, que buscamos fazer aparecer o que, na história de nossa cultura, permaneceu até agora mais escondido, mais oculto, mais profundamente investido: as relações de poder. Curiosamente, as estruturas econômicas de nossa sociedade são melhor conhecidas, melhor inventariadas, melhor isoladas que as estruturas do poder político. Gostaria de mostrar [...] de que maneira relações políticas foram estabelecidas e foram profundamente investidas em nossa cultura, dando lugar a uma série de fenômenos que somente podem ser explicados se os colocarmos em relação, não com as estruturas econômicas, as relações econômicas de produção, mas com as relações políticas que investem toda a trama de nossa existência (Foucault, 2001a, p. 1422).

Ao escutar Foucault nessa conferência na PUC-Rio, temos a impressão de que a dinastia deixa de lado as relações econômicas. No entanto, pensamos que não se trata disso. Muito pelo contrário. Uma das singularidades da aula de 1972 é indicar que a "dinástica do saber" estuda os vínculos a serem estabelecidos entre a mais-valia, o sobressaber e o sobrepoder. Não se trata, portanto, de abandonar as relações econômicas ou isolá-las das relações de saber e de poder, mas de mostrar como elas são investidas por estas últimas. A diferença é que a relação do sobressaber e do sobrepoder com a mais-valia deixa de ser da ordem da infraestrutura e da superestrutura para dar lugar à ordem da imanência recíproca.

22 Foucault também se inspira em seus contemporâneos Gilles Deleuze e Félix Guatarri, e seu livro “L’AntiOedipe", para propor uma leitura não marxista do capitalismo e seu sistema de penalidade, assim como para testar uma hipótese não psicanalítica da análise de Édipo. Em certo aspecto, as noções de excesso de poder ou sobrepoder assim como excesso de saber ou sobressaber a partir das quais Foucault interpreta Édipo-Reicomo uma tragédia menos da ordem do complexo parental do que da ordem de uma dinasteia e da luta pelo poder político, pode ser lida como a relativização ou a redução de importância da categoria de mais-valia marxista. 
O sobressaber (o saber burocrático/administrativo, mas também o saber canônico das universidades) reforça o sobrepoder e sua produção (sua concentração por parte do Estado). Esse conceito de sobressaber - neste caso, a extração do saber técnico e empírico dos trabalhadores e sua reapropriação pelo patronado e pelos burocratas industriais - parece ter sido elaborado por Foucault a partir do conceito marxista da mais-valia. Afinal, não basta extrair do trabalhador sua "força de trabalho"; trata-se de extrair algo a mais: sua experiência, sua técnica, sua memória e seu saber. Esse saber, enquanto ele formava parte do trabalhador, era objeto de desqualificação; mas quando ele foi dele expropriado e tornado um saber industrial e patronal, tornou-se supostamente um saber nobre, neutro e desinteressado.

Foucault parece insinuar um paradoxo das relações de produção e, particularmente, da mais-valia com o par sobressaber/sobrepoder. De um lado, ele relativiza a importância dessas relações quando elas são situadas somente como a infraestrutura a ser reproduzida, em última instância, pelos aparelhos ideológicos do Estado, como pensa Althusser. De outro lado, porém, quando a mais-valia é pensada pela relação de imanência com o sobressaber e o sobrepoder, ela se torna um conceito decisivo. A mais-valia produz-se a partir de uma extração análoga àquela operada pelo saber-poder. Primeiro, porque a força de trabalho a ser explorada é associada aos saberes e técnicas a serem sujeitados; em seguida, porque o suplemento de poder, o sobrepoder, materializa-se pela moralização da vida operária. Essa última relação Foucault a desenvolve amplamente no curso do ano seguinte, "La société punitive", ao modo de uma genealogia da moral do trabalho.

Em 1972, porém, ele toma distância do conceito de reprodução althusseriano por meio de uma compreensão do poder como um jogo entre forças em que algumas se impõem sobre as outras, as destroem, as anulam ou delas se apropriam. Nesse terceiro nível, identificado por ocasião da análise das matrizes jurídicopolíticas, o que temos, escreve Foucault, é o "jogo indefinido de formação, deslocamento, circulação, concentração onde se produzem, sem cessar, os suplementos, excessos, reforços de poder e o aumento de saber, o excesso de saber, o sobressaber" (Foucault, 2015, p. 213).

A dinástica do saber poderia ser cotejada como um momento de passagem, de deslocamento, pelo qual Foucault ainda concebe o poder como algo negativo, aquilo que reprime ou extrai uma força em proveito de outra. Somente no curso de 1973 é que encontramos uma relação positiva entre relações de produção e relações de poder-saber. O poder-saber não é somente a reprodução das relações de produção, posto que ele também atua pela extração, expropriação e repressão. O poder-saber entrecruza-se com as relações de trabalho por meio 
da produção de uma moral, a moral punitiva do trabalho, como suplemento de poder que garante o excesso do capital. A partir de então é que podemos visualizar o trânsito da dinástica do saber para a genealogia do poder.

\section{Referências}

ALTHUSSER, L. "Sur la Reproduction”. Préface d'Etienne Balibar; introduction de Jacques Bidet. Paris: PUF, 2011.

ARISTÓTELES. "Ética a Nicômaco". Coleção Pensadores. Tradução de Leonel Vallandro e Gerd Borheim da versão inglesa de W. D. Rosá. São Paulo: Abril Cultural, 1973. pp. 245-436.

BALIBAR, E. “Lettre d'Etienne Balibar à l'éditeur du cours”. In: M. Foucault, 2015. pp. 286-287.

BEHRENT, M. "Le libéralisme sans l'humanisme: Michel Foucault et la philosophie du libre marché, 1976-1979”. In: D. Zamora (ed.), 2014. pp. 37-85.

CHRISTOFFERSON, M. S. "Les intellectuels contre la gauche : l'idéologie antitotalitaire en France (196861981)". Marseille: Agone, 2014.

. "Foucault et 'la nouvelle philosophie': pourquoi Michel Foucault soutient Les maïtres penseurs d'André Glucksmann”. In: D. Zamora (ed.), 2014. pp. 13-35.

DEFERT, D. "Chronologie”. In: M. Foucault. Dits et écrits I, 2001. pp. 13-90.

. "Une vie politique. Entretiens avec Philippe Artières et Eric Favereau, avec la collaboration de Joséphine Gross". Paris: Seuil, 2014.

DORON, C.-O. "Notes et appareil critique". In: M. Foucault, 2015.

ERIBON, D. "Michel Foucault". Paris: Flammarion, 1989.

. "Michel Foucault e seus contemporâneos". Tradução de Lucy Magalhães. Rio de Janeiro: Jorge Zahar, 1996.

EWALD, F., HARCOURT, B. "Situation du cours". In: M. Foucault, 2015. pp. 243-282. FARGE, A., FOUCAULT, M. (ed.). (1982). "Le désordre des familles: Lettres de cachet des Archives de la Bastille au XVIIIème siècle". Edition revue. Paris: Gallimard, 2014. FOUCAULT, M. "Les mots et les choses". Paris: Gallimard, 1966.

. "L'Archéologie du savoir". Paris: Gallimard, 1969.

"Histoire de la folie à l'âge classique". Paris: Gallimard, 1972.

. "Il faut défendre la société. Cours au Collège de France, 1975-1976". Édition

établie sous la direction de François Ewald et Alessandro Fontana, par Mauro Bertani et Alessandro Fontana. Paris: Gallimard/Seuil, 1997.

. "Dits et écrits I". Edition établie sous la direction de Daniel Defert et François

Ewald avec la collaboration de Jacques Lagrange. Paris: Quarto/Gallimard, 2001a.

"Par-delà du bien et mal". In: M. Foucault, 2001a. pp. 1091-1104.

. "Manifeste du G.I.P.” In: M. Foucault, 2001a. pp. 1042-1043.

"La vérité et les formes juridiques". In: M. Foucault, 2001a. pp. 1406-1514.

. "Dits et écrits II". Edition établie sous la direction de Daniel Defert et François

Ewald avec la collaboration de Jacques Lagrange. Paris: Quarto/Gallimard, 2001 b. 

pp. 86-89.

. "Michel Foucault, 1'illégalisme et 1'art de punir”. In: M. Foucault, 2001b.

. "La vie des hommes infâmes", Les Cahiers du Chemin, n. 29, pp. 12-29, 15 janvier 1977. Reeditado em M. Foucault, 2001b, pp. 237-253.

. "Leçons sur la volonté de savoir suivi de Le savoir d'Oedipe". Édition établie sous da direction de François Ewald et Alessandro Fontana, par Daniel Defert. Paris: Gallimard/Seuil, 2011.

"Mal faire, dire vrai: Fonction de l'aveu en justice". Édition établie par Fabienne Brion e Bernard E. Harcourt. Louvain: Press Universitaire Louvain, 2012. pp. 235-246. . "La société punitive. Cours au Collège de France. 1972-1973". Édition établie sous da direction de François Ewald et Alessandro Fontana, par Bernard E. Harcourt. Paris: EHESS/Gallimard/Seuil, 2013.

. "Théories et institutions pénales. Cours au Collège de France. 1971-1972". Edition établie sous la direction de François Ewald et Alessandro Fontana, par Bernard E. Harcourt avec la collaboration de Elisabetta Basso (transcription du texte), ClaudeOlivier Doron (notes et appareil critique), et le coucours de Daniel Defert. Paris: EHESS/Gallimard/Seuil, 2015.

FOUCAULT, M. (ed.) (1978). "Herculine Barbin dite Alexina B, suivi de Un scandale au convent, d'Oscar Panizza (2002)". Préface de Michel Foucault e Postface d'Eric Fassin. Paris: Gallimard, 2014.

GARO, I. "Foucault, Deleuze, Althusser \& Marx: la politique dans la philosophie". 2 éd. Paris: Demopolis, 2011.

GROS, F. "Foucault et la société punitive”. Pouvoirs, 135, 2010/4, pp. 5-14 [Online]. Disponível em: http://www.cairn.info/revue-pouvoirs-2010-4-page-5.htm. (Acessado em 10 de março de 2016).

LEONARDI, E. "Cronache da un eterno presente. Usages et mésusages de la mise en contexte historique dans Daniel Zamora (a cura di), Critiquer Foucault. Les années 1980 et la tentation néolibérale, Aden, Bruxelles 2014 (468 p.)”. Materiali Foucaultiani. Disponivel em: http://www.materialifoucaultiani.org/fr/component/content/article/234daniel-zamora-critiquer-foucault.html (Acesso em 10 de março de 2016).

MACEY, D. "The lives of Michel Foucault". Hutchinson, 1993. Tradução para o francês de Pierre-Emmanuel Dauzat, Michel Foucault. Paris: Gallimard, 1994.

MILLER, J. "The passion of Michel Foucault”. Harvard: Harvard University Press, 2000. PICARD, N. "Ouvertures pour une société emprisonnée_sur: Michel Foucault, La Société punitive. Cours au Collège de France, 1972-1973". Acta Fabula, 10, décembre 2014 [Online] Disponível em: https://www.fabula.org/acta/document9046.php (Acesso em 10 de março de 2016).

ZAMORA, D. (ed.) “Critiquer Foucault: les années 1980 et la tentation néolibérale”. Bruxeles: Éditions Aden, 2014. 